Ethiopian Journal of Environmental Studies \& Management 8(Suppl. 1): 810 - 815, 2015.

ISSN:1998-0507

doi: http://dx.doi.org/10.4314/ejesm.v8i1.8S

Submitted: June 11, 2015

Accepted: October 14, 2015

\title{
ASSESSMENT OF OCCUPATIONAL EXPOSURE TO AIRBORNE PARTICULATES OTHERWISE NOT CLASSIFIABLE AT AN IRON AND STEEL INDUSTRY IN ZIMBABWE
}

\author{
*KANDA, A., MASIKE, C.B. AND NCUBE, F. \\ Department of Environmental Science, Bindura University of Science Education, P. Bag \\ 1020, Bindura, Zimbabwe
}

\begin{abstract}
Operations in the iron and steel industry generate and potentially expose employees to airborne particulates not otherwise classifiable (PNOC) which may contain various forms of silica that have been implicated for respiratory diseases. This study assessed occupational exposure to PNOC fractions $\left(P M_{5}, P M_{10}\right)$ and compliance to national occupational exposure limits (OEL) in five workstations at an iron and steel industry. Personal dust samples were collected using standard procedures in three 2hour periods of an 8hour work shift and gravimetrically analysed to estimate time-weighted averages. The highest mean concentrations of PNOC for PM $5\left(0.65 \pm 0.29 \mathrm{mg} / \mathrm{m}^{3}\right)$ and $P M_{10}\left(2.88 \pm 0.97 \mathrm{mg} / \mathrm{m}^{3}\right)$ recorded for employees at the Box Vibrator in the foundry were significantly lower than the national OELs for PNOC for both $P M_{5}\left(5 \mathrm{mg} / \mathrm{m}^{3}\right)$ and $P M_{10}\left(10 \mathrm{mg} / \mathrm{m}^{3}\right) \quad(p<0.05)$. So were the least concentrations of PNOC for both $P M_{5}\left(0.004 \pm 0.001 \mathrm{mg} / \mathrm{m}^{3}\right)$ and $P M_{10}\left(0.71 \pm 0.38 \mathrm{mg} / \mathrm{m}^{3}\right)$ recorded at the Administration ( $p<0.05)$. Employees across all the five workstations were not exposed to significantly high concentrations of PNOC when compared to national OELS $(p<0.05)$. However, the health risk associated to occupational exposure levels of employees can only be ascertained when specific components of the respirable PNOC are estimated. The concentrations of PNOC fractions to which employees were exposed to were generally a function of distance from the source.
\end{abstract}

Key Words: Occupational exposure, $P M_{5}, P M_{10}$, Respirable dust

\section{Introduction}

Operations in the iron and steel industry produce mixtures of airborne fractions of dusts classified by NSSA (2009) as particulates not otherwise classified (PNOC). Handling of raw materials, casting, moulding and shaking out, abrasive blasting, fettling, furnace installation and repair expose employees to sand and refractory materials which contain crystalline silica (NIOSH, 2002). Crystalline silica has been implicated for occupational and dermatological diseases (HSE, 1999; NIOSH, 2002; 2015). The main route of exposure to airborne dust is

*Corresponding author: Kanda, A.

Email: alzkanda@gmail.com through the respiratory mechanism (Calvert et al., 2003; Zakaria et al., 2005). The potential hazard of respirable dust to the lungs depends on the characteristics of the dust, duration of exposure, physiology of individual and work habits (Calvert et al., 2003; NSSA, 2009; Benson, 2012; Muinga et al., 2012).

Occupational exposure to dust in the iron and steel industry has mainly been recorded in foundries (Gomes et al., 2001; Zakaria et al., 2005; McGlothlin et al., 2012) where silica is chiefly exploited. However, employees at other workstations may be at a health risk due to fugitive 
dusts. It is dust which is in the breathing zone or entering the respiratory system which may pose health risks to the employee and should therefore be assessed and monitored. Dust control measures that could be process, engineered, personal, administrative or otherwise may help to protect the health of employees. Most industries in Zimbabwe have closed down due to operational challenges and a harsh economic environment, skyrocketing unemployment levels. The enforcement of work safety regulations, maintenance of safe working conditions by both employees and employers under such conditions by a few industries that are still operating may be compromised putting employees at a health risk.

In this work we assessed the occupational exposure of employees at five workstations at an iron and steel industry to dust fractions of PONC $\left(\mathrm{PM}_{5}\right.$ and $\left.\mathrm{PM}_{10}\right)$ in the absence of engineered dust preventive and control systems. We then evaluated the compliance of employees' occupational exposure to national occupational exposure limits (OELs). The foundry workstation used washed and graded river sand containing over $90 \%$ silica. Processing silica in the foundry generated dust in the breathing zone of employees that contained about $15 \%$ free crystalline silica determined by X-ray diffraction (NIOSH, 2002) from five randomly selected personal samples at the five workstations.

\section{Materials and Methods}

The concentrations of both $\mathrm{PM}_{5}$ and $\mathrm{PM}_{10}$ were estimated during normal working hours in June 2014. Three employees were randomly chosen from each workstation in the Foundry (Box Vibrator: 30\%, Fettling: $30 \%$ and Moulding: 30\%), Rolling Mills (15\%) and the Administration (7.5\%). Dust samples were taken in three 2 hour periods (9- 11a.m, 12-2p.m and 3-5p.m.) during a normal 8hour work shift. Two-hour air samples were collected using an SKC airsampling pump at a flow rate $2 \mathrm{~L} /$ minute. The pump had earlier been calibrated using internal and external flow meters with weighed filters. The sampler was mounted to the collar within the breathing zone of the employee with the inlet of the cyclone maintaining a downward vertical position. The $\mathrm{PM}_{10}$ fraction was collected using a 3piece dust collector with $37 \mathrm{~mm}$ glass fibre and the $\mathrm{PM}_{5}$ fraction using a cyclone dust collector with polyvinyl chloride filters (37mm).

After two hours of sampling, the sampling train was removed from the employee with the air flow rate recorded. The loaded filters were sealed tightly in closed cyclone filter holders and sent to the laboratory for quantification. In the laboratory, the loaded filters were carefully removed from their holders using forceps in a dust-free area. The holders were packed into a well-labelled rigid container with sufficient soft packing material to prevent crushing and vibration. Dust samples were analysed gravimetrically using the filter membrane method (HSE, 2000). Dust counts were done using a microbalance (Metter AE 163) by reweighing the dust filter for dust that had accumulated. The concentration of dust was determined as the difference in mass between the dust-loaded filter and the same initially unloaded filter, expressed as a fraction of the total volume of air sampled in two hours and expressed as $\mathrm{mg} / \mathrm{m}^{3}$. Post calibration was done to check the flow rate before the pump was charged again for the next sampling event.

Data were tested for normality (Q-Q plots, Kolmogorov-Smirnov) and equality of variance (Levene's test) and a one-way Analysis of Variance was performed to evaluate for statistical differences in mean exposure among five workstations (Box 
Vibrator, Moulding, Fettling, Rolling Mills and Administration) with three employees. The LSD post hoc procedure was used to separate treatment means at $\mathrm{p}<0.05$. A one sample $t$ test was used to determine any significant differences in mean concentrations of dust fractions at each workstation against national OELs. The IBM SPSS Statistics version 21 was used for all the statistical analyses.

\section{Results and Discussion}

Table 1 shows the occupational exposure of employees to fractions of PNOC $\left(\mathrm{PM}_{5}\right.$ and $\left.\mathrm{PM}_{10}\right)$ across five workstations and an assessment of their compliance to national OELs at an iron and steel industry. The highest and lowest mean concentrations of fractions of PNOC $\left(\mathrm{PM}_{5}\right.$ and $\left.\mathrm{PM}_{10}\right)$ were recorded at the Box Vibrator and the Administration respectively. The concentrations of occupational $\mathrm{PM}_{5}$ were significantly different across workstations $(\mathrm{p}<0.05)$, except between the Fettling and Moulding workstations. For the $\mathrm{PM}_{10}$ fraction, there were not significantly different dust concetrations amongst the Box Vibrator, Moulding and Fettling; between the Moulding and Rolling Mills; and between the Rolling mills and the Administration workstations $(\mathrm{p}>0.05)$.

Table 1: The concentrations of occupational dust fractions $\left(\mathrm{PM}_{5}\right.$ and $\left.\mathrm{PM}_{10}\right)$ of PNOC at five workstations at an iron and steel manufacturing industry in June 2014, Zimbabwe. Values are expressed as mean $\pm \mathrm{SE}\left(\mathrm{mg} / \mathrm{m}^{3}\right)$ for three measurements.

\begin{tabular}{|c|c|c|c|c|}
\hline \multirow[t]{2}{*}{ Workstation } & \multicolumn{2}{|c|}{$\begin{array}{l}\text { Mean exposure concentration of } \\
\text { PONC fractions }\left(\mathrm{mg} / \mathrm{m}^{3}\right)\end{array}$} & \multicolumn{2}{|c|}{$\begin{array}{l}\text { Significant difference with national (NSSA, } \\
2009) \text { OELs }\left(\mathrm{mg} / \mathrm{m}^{3}\right) p \text {-values }\end{array}$} \\
\hline & $\mathrm{PM}_{2.5}$ & $\mathrm{PM}_{10}$ & $\mathrm{PM}_{5}(5)$ & $\mathrm{PM}_{10}(10)$ \\
\hline Box Vibrator & $0.65 \pm 0.03^{\mathrm{a}}$ & $2.88 \pm 0.97^{\mathrm{v}}$ & $0.00 *$ & $0.00 *$ \\
\hline Fettling & $0.41 \pm 0.03^{\mathrm{b}}$ & $2.15 \pm 0.09^{\mathrm{v}}$ & $0.00 *$ & $0.00 *$ \\
\hline Moulding & $0.44 \pm 0.03^{\mathrm{bc}}$ & $1.97 \pm 0.34^{\mathrm{vw}}$ & $0.00 *$ & $0.00 *$ \\
\hline Rolling Mills & $0.27 \pm 0.02^{\mathrm{d}}$ & $0.63 \pm 0.04^{\mathrm{yw}}$ & $0.00 *$ & $0.00 *$ \\
\hline Administration & $0.004 \pm 0.001^{\mathrm{e}}$ & $0.07 \pm 0.03^{\mathrm{y}}$ & $0.00 *$ & $0.00 *$ \\
\hline
\end{tabular}

Similar superscripts aa, ab... down the column denote not significantly different at $\mathrm{p}<0.05$ confidence limit

Different superscripts $a, b, c \ldots$ down the column denote significant differences at $\mathrm{p}<0.05$ confidence limit

$*$ denotes significantly different $(\mathrm{p}<0.05)$

NSSA: National Social Security Authority,

PONC: Particulates Not Otherwise Classified

The concentrations of $\mathrm{PM}_{5}$ varied in the order: Box vibrator $>$ Fettling $=$ Moulding > Rolling Mills > Administration. For the $\mathrm{PM}_{10}$ fraction, the order was: Box vibrator $=$ Fettling $=$ Moulding $>$ Rolling Mills = Administration (Table 1). The concentration of dust has been reported to decrease with increasing distance from the source (Gholami et al., 2012; Hamzah et al., 2014). All workstations at the steel manufacturing industry had significantly lower concentrations of both $\mathrm{PM}_{5}$ and $\mathrm{PM}_{10}$ than the stipulated national OELs; 5 and $10 \mathrm{mg} / \mathrm{m}^{3}$ respectively (NSSA, 2009). The lowest $\mathrm{PM}_{10}$ concentration was recorded at the Administration that was located about $800 \mathrm{~m}$ away from the dust generating Box Vibrator. The enclosed offices could only allow the entry of fugitive dusts particularly of very small aerodynamic diameter, thus $\mathrm{PM}_{5}$, through ventilation systems. The larger $\mathrm{PM}_{10}$ dust particles cannot spend longer periods in the 
atmosphere, and the breathing zone of the employee, therefore could not travel for long distances, unless there is enough driving energy from wind. Respirable crystalline silica dust is the most fatal due to its ability to penetrate further in to the respiratory system to regions where damage is irreversible (Yassin et al., 2005) as it passes through all defensive mechanisms of the respiratory system (nose-alveolus) developing acute silicosis when excessively absorbed within a short period of time (Sakwari et al., 2011).

The extent of occupational exposure becomes a function of the available dust in the breathing zone and the rate of dust generation among many other factors. The rate of dust generation has also been found to increase with the energy associated with the process in question (HSE, 1999) making the box vibrator the major contributor. Foundries, where the Box Vibrator is housed, are the main sources of dust generation (Gomes et al., 2001; Moroni et al., 2014). The $\mathrm{PM}_{5}$ dust fraction decreased with distance from the source possibly because of both physical barriers such as outbuildings, vegetation and environmental factors (WHO, 1999; Guo and Maghirang (2012). The absence of engineered control systems at the point of generation could possibly explain the high levels of PONC in the foundry (Box Vibrator, Moulding and Fettling) than the set OELs. Once dust is airborne, its control becomes problematic. The prevention of dust emission, however impossible, may be potentially the best way to reduce the exposure of employees to high dust concentrations (WHO, 1999).

The statistically non-significant difference in the concentrations of PONC for both $\mathrm{PM}_{5}$ and $\mathrm{PM}_{10}$ recorded at the Moulding and Fettling workstations could have been because of their close proximity (6m) within the foundry. The contribution of dispersion of dust from the Box Vibrator as fugitive dust (WHO, 1999) could explain the appearance of PONC at the Rolling Mills, about $80 \mathrm{~m}$ away from the box vibrator. The significantly lower concentrations of fractions of PONC than the national TLVs at all workstations may not mean that all workers are safe since they may be exposed to very low concentrations of toxic PONC which accumulate in their bodies only to show effects years later. There are also other stressors not characterised in the dusts that potentially expose employees to health risk (Gomes et al., 2001). The use of PONC to assess employee exposure may play a pivotal role where analytical methods and equipment in many settings may be limiting, despite its limitations of inability to determine the health risk index for specific exposure to dust components.

\section{Conclusion and Recommendations}

Findings from this assessment showed that time-weighted averages for an 8hour shift (TWA-8) exposure to fractions of PONC in the five workstations at an Iron and Steel industry were within national (Zimbabwean) OELs defined by NSSA (2009). The limitation of using PONC to assess employee health risk due to exposure was evident as it can be misleading since the chemistry and components of the dust will be unknown. Certain toxic substances present in respirable dust in very small concentrations may not be detected but potentially expose employees to health risk. The health risk may increase at such points as the point of generation yet using PNOC may show low exposure values. The study seems to further agree with other studies that airborne dust concentrations decrease with particle size and distance from the source. In light of the above findings we recommend that free 
crystalline silica in the respirable fraction of PONC of employees at each workstation be quantified in order to assess the health risk due to occupational exposure using various indices. We further suggest periodic medical examinations of workers in the foundry for the risk of developing respiratory diseases.

\section{References}

Benson, J.M. (2012). Safety consideration when handling metal powders, Journal of African Institute of Mining, 112(7): 563-575.

Calvert, G.M., Rice, F.L., Boiao, J.M., Sheehy, J.W. and Sanderson, W.T. (2003). Occupational silica exposure and risk of various diseases: An analysis using death certificates from 27 states of the United States. Occupational Environmental Medicine, 60: 122-129.

Gholami, A., Fani, M.J. and Sadeghi, N. (2012). Occupational exposure determination of silica dust in an iron-stone ore and comparison with standard, International Journal of collaborative Research on Medicine and Public Health, 4(6): 1141-1149.

Gomes, J., Lloyd, O.L., Norman, N.J. and Pahwa, P. ( 2001). Dust exposure and impairment of lung function at a small iron foundry in a rapidly developing country, Occupational and Environmental Medicine, 58: 656-662.

Guo, L. and Maghirang, R.G. (2012). Numerical simulation of airflow and particulate collection by vegetative barrier, Engineering Applications and Computational Fluid Mechanics, 6(1): 110-122.

Hamzah, N.A., Mohd Tamrin, S.B. and Ismail, N.H. (2014). Metal dust exposure and respiratory health of male steel workers in Terenggana,
Malaysia, Iranian Journal of Public Health, 43(3): 154-166.

Health and Safety Executive (HSE) (1999). Hazard prevention and control in the work environment: Airborne dust, MDHS series, HSE books, Sheffield.

Health and Safety Executive (HSE) (2000). General methods for sampling and gravimetric analysis of respirable and inhalable dust 14/3: Methods for the determination of hazardous substances, MDHS series, HSE books, Sheffield.

McGlothlin, J.M. (ed.) (2012). Case study: Evaluation and control of respiratory silica exposure during lateral drilling of concrete, Journal of Occupational and Environmental Hygiene, 9: D35D41.

Moroni, B., Viti, C. and Cappelletti, D. (2014). Exposure Vs toxicity levels of airborne quartz, metal and carbon particles in cast iron foundries, Journal of Exposure Science and Epidemiology, 24: 42-50.

Muinga, C., Rice, C., Lentz, T., Lockey, J., Niermier, R. and Succop, P. (2012). Checklist Model to improve work practices in small scale demolition operations with silica dust exposures, International Journal of Environmental Research and Public Health, 9: 585-595.

NIOSH (2002). Health effects of occupational exposure to respirable crystalline silica, Department of Health and Human Services, Centres for disease control and prevention, National Institute of Occupational Safety and Health, No. 2002-129, Cincinnati.

NIOSH (2015). Best practice engineering control guidelines to control worker exposure to respirable crystalline silica during asphalt pavement milling. Cincinnati, OH: U.S. 
Department of Health and Human Services, Centres for Disease Control and Prevention, National Institute for Occupational Safety and Health, DHHS (NIOSH) Publication No. 2015-105.

NSSA (2009). Guidance for occupational exposure limits (OEL) for dust and chemical substances in Zimbabwe, Guidance Notes, revision 1, National Social Security Authority, Harare.

Sakwari, G., Braytveit, M., Mamuya, S.H.D. and Moen, B.F.M. (2011). Dust exposure and chronic respiratory symptoms among coffee curing workers in Kilimanjaro: A cross sectional study, BMC Pulmonary Medicine, 11:54. http:www.biomedcentral.com/14712466/11/54

WHO (1999). Hazard Prevention and control in the work environment: Airborne dust.

WHO/SDE/OEH/99.14, World Health Organisation, Geneva, Switzerland Yassin, A., Yebesi, F. and Tingle, R. (2005). Occupational exposure to crystalline silica dust in the United States, 1988-2003, Environmental Health Perspectives, 113(3) : 255260.

Zakaria, A.M., Noweir, K.H. and ElMaghrabi, G. (2005). Evaluation of Occupational Hazards in Foundries, The Journal of the Egyptian Health Association, 80(4): 433-462. 